\title{
Antecedentes legales sobre enfermedades raras
}

\author{
Chilean juridical antecedents about rare diseases
}

Dentro de la plena vigencia del respeto a los derechos humanos y el establecimiento de mecanismos jurídicos que los cautelen, en nuestro ordenamiento jurídico se contempla la garantía constitucional de la protección de la salud de las personas, en el artículo $19 N^{\circ} 9$ de la Constitución Política de Chile de 1980 .

"El derecho a la protección de la salud.

El Estado protege el libre e igualitario acceso a las acciones de promoción, protección y recuperación de la salud y de rehabilitación del individuo.

Le corresponderá, asimismo, la coordinación y control de las acciones relacionadas con la salud. Es deber preferente del Estado garantizar la ejecución de las acciones de salud, sea que se presten a través de instituciones públicas o privadas, en la forma y condiciones que determine la ley, la que podrá establecer cotizaciones obligatorias.

Cada persona tendrá el derecho a elegir el sistema de salud al que desee acogerse, sea éste estatal o privado".

El criterio inspirador que se tuvo presente, fue que las acciones de promoción, protección y recuperación de la salud, y de rehabilitación cuando ello fuere necesario, sean brindadas por instituciones públicas y privadas y que coexistan sistemas de salud estatales y privados. En el tema de salud además se debe considerar la obligación de los médicos de procurar por todos los medios y técnicas que integran la lex artis médica, para cumplir con los fines de la medicina, se genera así un conjunto de derechos de las personas y tareas del Estado'.

En Chile, el sistema de Garantías Explícitas en Salud (GES), constituye un conjunto de beneficios garantizados por Ley a un conjunto de enfermedades determinadas principalmente por su alta prevalencia, lo que por definición excluye a las enfermedades raras.

La Ley 20.584, que Regula los derechos y deberes que tienen las personas en relación con acciones vinculadas a su atención en salud, no trata de esta problemática.

La Cobertura Adicional para Enfermedades Catastróficas (CAEC), en el caso de las Instituciones de Salud Previsional (Isapres) no otorgan cobertura a las exclusiones del contrato dentro de las cuales se encuentran, las no aranceladas por el Fondo Nacional de Salud (Fonasa), y se da la penosa situación que la mayoría de las enfermedades raras, no cuentan con un código o arancel Fonasa.

Esta triste realidad, ha significado que los afectados por estas enfermedades hayan buscado por sus problemas de salud, una igualdad de derechos a la protección de la salud, mediante la presentación de Recursos ante tribunales, o mediante el Decreto Exento 63/2015 del Ministerio de Salud el cual otorga auxilios extraordinarios; en ambos casos sin encontrar soluciones permanentes a los problemas de salud que los aquejan.

La Organización de las Naciones Unidas (ONU), creó el comité de ONG (organizaciones no gubernamentales) para las Enfermedades Raras en noviembre de 2016, con el propósito de lograr un mayor reconocimiento político de los retos de las enfermedades a nivel mundial, cuyos objetivos entre otros son aumentar la visibilidad de las enfermedades raras a nivel mundial, ampliar y compartir conocimientos sobre estas patologías y sus necesidades no atendidas, para establecer las enfermedades raras como una prioridad mundial en salud pública, investigación y políticas de atención médica y social. Anteriormente la Comisión Europea apoyó la iniciativa de colaboración Orphanet, que en el año 2000 creó un portal de información sobre enfermedades raras y medicamentos huérfanos; y el Consorcio Internacional de Investigación sobre Enfermedades Raras, dirigido a promover la investigación que en el año 2011 comenzó un proyecto conjunto de la Comisión Europea y los Institutos Nacionales de Salud de los Estados Unidos, Canadá y Japón entre otros países ${ }^{2}$. 
Ello permitirá que los criterios para definir las enfermedades raras, que hoy son diversos de uno a otro país; así como el alto impacto generado por las enfermedades raras tanto para quienes las sufren, como para su entorno, en aspectos biopsicosociales y económicos, no sean abordados parcialmente, sino con un enfoque global generando oportunidades para atender los problemas especificos que enfrentan las personas que viven con una enfermedad rara . $^{3}$

Las enfermedades raras, poco frecuentes, minoritarias o huérfanas si bien no cuentan con una definición en nuestro país, podemos encontrar antecedentes en el Boletín $N^{o} 7.643-11$, del Senado de la República, Proyecto de ley, iniciado en Moción de los Honorables Senadores señores Quintana, Walker, don Patricio, Chahuán, Rossi y Uriarte, sobre enfermedades poco frecuentes ${ }^{4}$; donde se refieren a ciertas enfermedades que afectan a los seres humanos, de una muy baja prevalencia en la población, y gran diversidad, citando las definiciones adoptadas por Unión Europea y Estados Unidos, y sus esfuerzos por un enfoque global y planes para estimular el desarrollo de drogas huérfanas. A nivel latino americano, Colombia adoptó una estrategia de tratar las enfermedades raras en conjunto 4 .

En nuestro país, la Federación Chilena de Enfermedades Raras, FECHER, integrada principalmente por los mismos pacientes y sus familiares, profesionales de la salud y personas sensibilizadas por el tema, busca constituirse en un canal para estos pacientes, habiendo participado activamente en la gestión de la Ley 20.850 conocida como "Ley Ricarte Soto”, creó un sistema de protección financiera para diagnósticos de alto costo, de cobertura universal, para el diagnóstico y tratamiento de 14 problemas de salud. Sin embargo, siendo una norma reciente que busca dar respuesta, no se ajusta a los criterios y soluciones que se espera sean entregados a nivel internacional, ya que las definiciones de esta ley están inspiradas en el costo y materias financieras ${ }^{5}$.

Si bien se han hecho esfuerzos, mediante la Ley 20.850, ellos no resultan suficientes para lograr la aspiración de la $O N U$, de garantizar que ninguna persona que viva con una enfermedad rara sea abandonada, por no ser capaces como sociedad de dar respuesta a sus problemas especificos, por el desafio que no es sólo económico, ya que estamos frente a un problema ético de una minoría que padece una enfermedad rara que mayoritariamente además de padecer una enfermedad que es grave, crónica y degenerativa, se puede llegar a provocar una reducción o pérdida de autonomía. Por ello, estas personas pudieran considerarse con una discapacidad por las barreras debidas a su condición y su participación plena y efectiva en la sociedad, lo que se traduce en no dejar de mencionar en esta revisión de antecedentes jurídicos de la "Convención sobre los derechos de las personas con discapacidad" y su propósito de promover, proteger y asegurar el goce pleno y en condiciones de igualdad de todos los derechos humanos y libertades fundamentales por todas las personas con discapacidad, y promover el respeto de su dignidad inherente ${ }^{6}$.

Gina Raineri Bernain

Abogado, Enfermera-Matrona y Magister en Bioética Secretaria Ejecutiva Comité de Etica de Investigación en Seres Humanos, Facultad de Medicina, Universidad de Chile.

\section{Bibliografía}

1.- EVANS DE LA CUADRA E. Los Derechos Constitucionales, Tomo II, $2^{\text {a }}$ Edición actualizada, Editorial Jurídica de Chile. Pág. 317 y siguientes

2.- OMS. Unidos para combatir las enfermedades raras. Boletín de la Organización Mundial de la Salud 2012, 90: 401-76. (Recopilación de artículos). Disponible en: http://www.who.int/bulletin/volumes/90/6/12-020612/ es/ (Consultado el 7 de abril de 2017).

3.- ONU. La ONU crea Comité para las Enfermedades Raras. ALIBER Disponible en: http://aliber.org/ web/2016/11/14/el-comite-de-ong-para-las-er-se-lanzaen-la-onu/ (Consultado el 6 de abril de 2017).

4.- QUINTANA L J, WALKER P P. Las enfermedades raras, poco frecuentes, minoritarias o huérfanas. Boletín del Senado $N^{o}$ 7.643-11. Disponible en: https:// www.google.cl/webhp?sourceid=chrome-instant\&ion= $1 \&$ espv $=2 \&$ ie $=$ UTF $-8 \# \mathrm{q}=$ Las + enfermedades + raras,$+p$ oco + frecuentes, + minoritarias $+\mathrm{o}+\mathrm{hu} \% \mathrm{C} 3 \% \mathrm{~A} 9$ rfanas $+\mathrm{s}$ e+definen, + en+Chile (Consultado el 6 de abril de 2017).

5.- FECHER. Federación Chilena de Enfermedades Raras. Disponible en: https://www.google.cl/webhp? sourceid $=$ chrome-instant $\&$ ion $=1 \&$ espv $=2 \&$ ie $=U T F-$ $8 \#$ safe $=$ off $\& \mathrm{q}=$ enfermedades + raras + chile + fecher (Consultado el 6 de abril de 2017).

6.- ONU. Convención sobre los derechos de las personas con discapacidad. Disponible en: http:/www.un.org/esa/ socdev/enable/documents/tccconvs.pdf (Consultado el 6 de abril de 2017). 